\title{
Figurações e transfigurações do espaço geopoético em Romance d'A Pedra do Reino e o príncipe do sangue do vai-e-volta, de Ariano Suassuna
}

\author{
Giuliarde de Abreu Narvaes \\ Universidade Estadual Paulista - Júlio de Mesquita Filho (UNESP - Brasil) \\ Universidade Fernando Pessoa (Portugal)
}

Resumo: A obra literária revela-se um território de imagens e de símbolos organizados e combinados entre si, cujas fronteiras indicam apenas uma ilusória interrupção no movimento contínuo das personagens e dos leitores que o habitam. Estes fazem parte de um imaginário geopoético gerador de efeitos de sentido diversos que, mesmo quando desvelada sua topografia literária (temas, motivos, cenários e intrigas), não se restringem a unívocas delimitações de lugares (espaços físicos) e momentos (tempos particulares), mas se revelam superfícies "transrepresentacionais", crivadas de ambiguidades e analogias, capazes de recobrir, ao mesmo tempo, uma diversidade de outros lugares e momentos. Nesta investigação, partimos da interpelação da realidade sertaneja enquanto figuração literária cada vez mais elaborada no plano de uma ação imaginante, verificando na abertura conferida à imaginação a ação poética do personagem ficcional sobre a realidade do sertão que o circunda e o consome.

Palavras-chave: Imaginário, Espaço geopoético, Memória, Imaginação, Cultura sertaneja

\begin{abstract}
The literary work is a territory of images and symbols arranged and combined among themselves, whose borders indicate only an illusory interruption in continuous movement of the characters and the readers who inhabit it. They are part of an imaginary geopoetic that generates effects of meaning that, even when revealed its literary topography (themes, motives, scenarios and plots), are not restricted to linearity of places (physical spaces) and time (particular times), but they are areas "transrepresentational", riddled with ambiguities and analogies, able to cover, at the same time, a variety of other places and moments. In this
\end{abstract}


research, we apprehend the reality of the north-eastern backwoods while literary figuration increasingly drawn in the plane of an imaginary action, noting in the opening given to imagination poetic action of the fictional character on the reality of the north-eastern backwoods that surrounds and consumes.

Keywords: Imaginary. Poetical land, Memory, Imagination, Popular culture

\section{Introdução}

A obra literária revela-se um espaço de imagens e de símbolos organizados e combinados entre si, cujas fronteiras indicam apenas uma ilusória interrupção no movimento contínuo das personagens e dos leitores que habitam esse território poético. Trata-se de um imaginário geopoético potencializador de efeitos de sentido diversos que, mesmo quando desvelada sua topografia literária (temas, motivos, cenários e intrigas), não se restringem a lugares (espaços físicos) univocamente delimitados e a acontecimentos específicos (fatos cronológicos), mas se revelam superfícies "transrepresentacionais", crivadas de ambiguidades e analogias capazes de recobrir, ao mesmo tempo, uma diversidade de outros locais e de outros acontecimentos. O livro Romance d'A Pedra do Reino e o príncipe do sangue do vai-e-volta, do escritor paraibano Ariano Suassuna, é eloquente exemplar desse território de profusões poéticas. Nessa obra, o nordeste sertanejo brasileiro é ambiente narrativo e espaço ficcional transfigurado constantemente pela própria prosa romanesca.

Nesse romance, Ariano Suassuna funde elementos constituintes das raízes culturais nordestinas (o lirismo improvisado do folheto de cordel, a etnologia imagética das xilogravuras, o carnavalesco e o risível do teatro popular) com os elementos que compõem a memória artística e literária de uma tradição intelectual brasileira e estrangeira, afeita a cânones e às inúmeras influências da cultura erudita ocidental. Tomando o espaço do nordeste rural como palco para a encenação de uma épica mambembe, Suassuna apresenta como regente de um extravagante universo ficcional a figura errante de um engenhoso rapsodo fidalgo-sertanejo, chamado D. Pedro Dinis Ferreira Quaderna, cuja imagística 
heráldica realiza, por meio do jogo dramático, do falsear poético dos fatos históricos e literários, e da conjunção de raízes genealógicas, telúricas e culturais, o que o próprio personagem denomina "romance-enigmático de crime e sangue".

A partir de um idealismo mitopoético, Quaderna reivindica para si o romântico epíteto de gênio da raça brasileira, buscando, em seu imaginário sertanejo, decifrar o passado histórico-lendário do qual é herdeiro de sangue, e profeticamente engendrar uma grandiosa epopeia em estilo régio, capaz de reunir na representação heroica e alegórica do povo e da história nacional suas origens indígena, negra e aristocrática portuguesa, concretizando, deste modo, o ideário da nacionalidade brasileira. Com o desejo de ser Rei, e ao mesmo tempo jogral, Quaderna enuncia sob a égide da imaginação criadora, ato que lhe permite transfigurar a realidade ficcional, sacralizá-la, expressar o sertão de dentro de si mesmo, como um sertão mítico que se encontra ordenado pelos próprios signos literários. Propomo-nos, portanto, a partir de uma leitura específica do Romance d'A Pedra do Reino, de Ariano Suassuna, realizar uma investigação sobre o modo como ocorre a fusão dos elementos constitutivos de um imaginário geográfico sertanejo por meio da própria atividade criativa que o origina, a imaginação, destacando, nesse imaginário literário, sua capacidade integradora, seu dinamismo organizador e sua potencialidade combinatória, responsáveis pelo valor poético que as imagens, os símbolos e o mito assumem quando transladados para o espaço lúdico da linguagem.

\section{Considerações iniciais: apontamentos sobre um conceito de imaginário}

Realizando uma investigação acerca do cinema enquanto fenômeno antropológico e cultural, Edgar Morin, sociólogo e filósofo construtivista francês, dá-nos, em $O$ Cinema ou $o$ homem imaginário, elucidações relevantes para as determinações do imaginário. A partir da concepção de realidade como constructo do espírito humano, Morin se mostra em acordo com o pensamento de Pierre Francastel, para quem a arte é o resultado de uma atividade

original do espírito. Segundo Morin, entra-se no reino do imaginário no momento em que as aspirações, os desejos, e os seus negativos, os receios e os terrores, captam e modelam a 
imagem, com vista a ordenarem, segundo a sua lógica, os sonhos, os mitos, as religiões, as crenças, as literaturas, ou seja, precisamente, todas as ficções (Morin 1970: 95ss).

A realidade objetiva, exterior ao indivíduo, está contida na imagem, seu estrito reflexo, ao passo que esta, mesmo em contradição com a extravagância imaginária, não deixa de ser consumida pela magia imagística. 0 imaginário é capaz de enfeitiçar a imagem, embebendo-a dos poderes subjetivos que a vão "deslocar, deformar e projetar para a fantasia e para o sonho." (Morin 1970: 96). Compreendemos que não apenas no cinema, como determina Morin, mas em quaisquer representações no campo da ficção, a imagem objetiva e sensitiva do mundo, como matéria ou corpo da linguagem, passa então no imaginário a aparentar-se com as imagens do sonho - "museu imaginário do nosso pensamento em infância" (ibidem). De certo modo, Morin nos conduz a uma releitura de aspectos presentes na obra de Sigmund Freud. Em A Interpretação dos Sonhos, o médico vienense propõe um método de análise do imaginário "noturno", ou seja, um imaginário do sonho, cuja decomposição dos elementos pode contribuir para a descoberta de significações ocultadas ou dissimuladas por conteúdos imagéticos pouco verossímeis. Trata-se, portanto, da análise de um imaginário que fabula, que se constitui da representação de imagens inventadas. Para Freud, as representações inconscientes são também denominadas "representações de coisas", pois se traduzem em imagens acústicas, táteis e principalmente visuais de "coisas ou pedaços de coisas impressas no inconsciente", e que constituirão a matéria com que se moldam os sonhos (cf. Nasio 1995: 22).

A pulsão, energia que dirige o psiquismo à procura do prazer instantâneo e absoluto (alívio para as tensões psíquicas), investe sobre tais representações, fazendo com que o imaginário onírico funcione segundo mecanismos de deslocamento e de condensação, a garantir, deste modo, a circulação livre da corrente pulsional no inconsciente. O imaginário ficcional possui mecanismos análogos aos propostos por Freud. Compondo-se dos mesmos constituintes fabulescos dos sonhos (tempo, espaço, personagens e ação), a imagética na representação ficcional molda-se, conforma-se, deforma-se e reinventa-se por meio dos efeitos semântico-metafóricos (condensação) e sintático-metonímicos (deslocamento) próprios da linguagem poética ${ }^{1}$, os quais, quando interpretados, numa investigação dos 
efeitos de sentido subjacentes à representação, podem desvelar as motivações subjetivas do sujeito imaginante, aquele que, na obra literária, se faz comunicar por meio das imagens textuais. Estas determinam sua imaginação leitora e participam da criação do próprio mundo que o envolve.

De certo modo, parafraseando Edgar Morin, poderíamos concluir que é por meio da exegese que encontramos as aspirações, os desejos, os medos e receios que, pela imaginação dos narradores e personagens, modelam as imagens-textos que compõe o imaginário de uma obra literária, passível de ser sempre reimaginado pelos outros imaginários que o leem e nele encontram alguma reflexão. Para o filósofo Jean-Jacques Wunenburger,

o estudo do imaginário como mundo de representações complexas deve, pois, fundar-se no sistema das imagens-textos, em sua dinâmica criativa e sua riqueza semântica, que tornam possível uma interpretação indefinida, e, por fim, em sua eficácia prática e sua participação na vida individual e coletiva. (Wunenburger 2007: 12)

Propondo uma leitura arquetípica próxima à psicanálise jungiana, e afastando-se de certa passibilidade característica das imagens noturnas do inconsciente de Freud, Gaston Bachelard ressalta o poder de transformação das imagens quando postas, por uma consciência perceptiva, em contato com a materialidade do mundo exterior. Bachelard, de modo semelhante a Morin, ao declarar que a imaginação não é a faculdade de formar imagens, mas de deformar as imagens fornecidas pela percepção, observa que ao retirar as primeiras imagens do universo sensível, profundamente limitado, a imaginação carrega-as de intensidade afetiva e as liberta. Libertação compreendida como uma ação imaginante que modifica as formas originais das imagens, propondo combinações inesperadas e até aberrantes entre elas, a organizar de imediato a relação dessas imagens modificadas com o mundo exterior. Bachelard assinala que "o vocábulo fundamental que corresponde à imaginação não é imagem, mas imaginário." (Bachelard 1990: 1). Para o filósofo, graças ao imaginário, a imaginação é inerentemente aberta, expansiva, mediadora da experiência da 
novidade no mundo psíquico: "Imaginar é ausentar-se, é lançar-se a uma vida nova” (idem: 3).

Seguiremos, pois, com mais algumas proposições acerca do lugar da geopoética nas investigações sobre a imaginação propostas por Bachelard, desta vez integrando-as a um breve exercício de análise de duas passagens da obra Romance d'A Pedra do Reino e o príncipe do sangue do vai-e-volta, de Ariano Suassuna.

\section{A geopoética do imaginário no Romance de Ariano Suassua}

A primeira passagem do Romance de Suassuna a ser investigada refere-se ao momento em que a personagem Dom Pedro Dinis Ferreira Quaderna, narrador e protagonista do romance, realiza uma excursão pelas paisagens áridas do Sertão do Cariri nordestino até as serras do condado de Princesa, buscando encontrar as famosas Pedras do Reino, que não seriam para ele nada menos que as torres de pedra do castelo soterrado e encantado do reino sertanejo, do qual ele mesmo é herdeiro de sangue:

Naquele primeiro momento, porém, a decepção foi dura. 0 padre desenhara as duas pedras de frente, uma quase igual à outra, e parecendo ambas, de fato, as torres de pedra da Catedral Soterranha do meu Reino. Acontece que, lá, ficando a gente na posição da gravura, as duas pedras se apresentavam bastante diferentes, uma muito mais larga, e a mais fina com uma torção que, no topo, desfigurava a imagem ideal e gloriosa que eu forjara em meu sangue, durante todos aqueles anos, confiado nas Epopeias que homens conspícuos e acadêmicos tinham escrito. (...). Para surpresa minha, porém, Euclydes [Villar] discordou de mim. Achava as pedras, assim paralelas, maciças e de cor férrea, 'terrivelmente impressionadoras', talvez porque, sem ter lido antes o que eu lera, nunca esperara demais, nem criara, a respeito delas, as imagens gloriosas, monárquicas e prateadas que eu alimentara em meu sangue. (...). Segundo Villar, assim era o Mundo e assim era a Literatura! Nas coisas do mundo, os "chuviscos de prata" nunca ou raramente existiam, e o "sangue vermelho das pedras, conservado vivo e fresco durante todo o tempo" era sempre, de fato, na mesquinha realidade, simples mijo-de-mocó ${ }^{2}$. Se a gente não mentisse um pouco, “ajudando as pedras tortas e manchadas do real a brilharem no sangue vermelho e na prata, nunca elas seriam introduzidas no Reino Encantado da Literatura!" (Suassuna 2010: Folheto XXI, 147ss)

Neste trecho, interessa-nos, por ora, verificar a tensão que se estabelece entre o 
imaginário subjetivo, construído pela assimilação afetiva e criativa de imagens oriundas de um imaginário literário, este também enriquecido pela imaginação, e as imagens originais, percebidas a partir do mundo real e que, aos olhos de um indivíduo comum, incapaz de (des)figurar a imagem produzida, apresentam-se sóbrias e estáticas, como imagens que, para um sonhador, não seriam mais que uma decepcionante percepção sem devaneio.

A ação dramática que encontramos nesse trecho do romance notavelmente permite uma reflexão sobre a ideia de "ação imaginante" ou "imaginação", a qual se encontra muito próxima da proposta por Bachelard em seus ensaios. Segundo o pensador francês,

Se não há mudança de imagens, união inesperada das imagens, não há imaginação, não há ação imaginante. Se uma imagem presente não faz pensar numa imagem ausente, se uma imagem ocasional não determina uma prodigalidade de imagens aberrantes, uma explosão de imagens, não há imaginação. Há percepção, lembrança de uma percepção, memória familiar, hábito das cores e das formas. (Bachelard 1990: 1)

No trecho destacado da obra de Suassuna, duas personagens, Pedro Quaderna e Euclydes Villar, apresentam imaginários de intensidades diferentes. Quaderna, influenciado pelo imaginário épico que o concerne, expressa uma imaginação discreta, porque se encontra excessivamente arraigado nas fontes imagéticas das epopeias literárias, e hesita imaginar a partir da realidade imediata. Nessa passagem, a personagem não realiza a ação imaginante necessária às livres combinações da matéria imagética, pródiga aos exageros do espírito, e assim decepciona-se com o que vê. Pois, num quixotismo às avessas, o herói recusa-se a exercitar, na realidade imediata, a mesma ação imaginante que, no imaginário épico literário, deformou e transfigurou as "pedras tortas e manchadas" em torres de uma catedral soterrada.

Para Gaston Bachelard, a palavra afirma-se como o poder criativo das imagens no espírito, e a literatura impõe-se como uma das categorias da imaginação criadora. Enquanto descrição "honesta" do que se vê, presa à presença da matéria encovada sob o fundo estático e ordinário do real, a imagem definitiva subtrai a potencialidade criativa da imaginação, que movimenta e reordena a imagem no espírito, figurando- $\mathrm{a}^{3}$. Quaderna anuncia a incompatibilidade subversiva e degradante do mundo real com seu imaginário 
epopeico: a imagem descrita "desfigurava a imagem ideal e gloriosa que eu forjara em meu sangue" (Suassuna 2010: Folheto XXI, 147). Imaginar caracteriza-se, sobretudo, por um ausentar-se do mundo (cf. Bachelard 1990: 3).

Euclydes Villar, por sua vez, possuidor de um imaginário destituído de tantos matizes épicos, revela um olhar pródigo ao exercício da imaginação. Mesmo não sendo uma ação imaginante tão gloriosa e monárquica, como a revelada por Quaderna, traz no frescor de seu olhar uma importante lição para o amigo: uma autêntica disposição a imaginar a realidade do mundo. Na passagem supracitada, "as pedras", enquanto signo de um elemento percebido no mundo ordinário, constituem-se como forma imagética a partir da interação com outros elementos linguísticos que orbitam seu campo sintático-semântico ("paralelas", "maciças", "de cor férrea"), fazendo com que a imagem original (natural) saia de seu estado de repouso e passe a mover-se em um meio de significação enriquecido pelas possibilidades dinâmicas de combinação. As pedras, como imaginadas por Euclydes Villar, figurativizam-se e ganham singularidade ao destacarem-se da realidade e se imporem em seu imaginário com equilíbrio, rigor e crueldade 4 . Deste modo, Villar realiza uma ação imaginante, imprescindível à criação literária, pois vê tais pedras como duplos terrivelmente impressionadores das pedras originais pertencentes ao real. Para Bachelard, A propósito de qualquer imagem que nos impressiona, devemos indagar-nos: qual o arroubo linguístico que essa imagem libera em nós? Como a separamos do fundo por demais estável das recordações familiares? Para bem sentir o papel imaginante da linguagem, é preciso procurar pacientemente, a propósito de todas as palavras, os desejos de alteridade, os desejos de duplo sentido, os desejos de metáfora (ibidem).

As pedras da serra do condado de Princesa passam a ausentar-se do mundo real quando entram no reino do imaginário e tornam-se imagens figuradas, encantadas pelo poder metafórico da poiesis. É “a imaginação literária, a imaginação falada, aquela que, atendo-se à linguagem, forma o tecido temporal da espiritualidade e que, por conseguinte, se liberta da realidade." (idem: 2). Como em um dos inúmeros diálogos em que Sancho Pança busca compreender o delírio tresloucado de seu amo, Euclydes Villar faz notar a Pedro Quaderna que o imaginário literário começa com o devir do real, com o exercício de 
falsear as impressões da realidade imediata para que esta possa vir a transmutar-se em expressividade livre e mágica no reino do imaginário. Ao falsear as percepções originais, no sentido de fazer-lhes alterações ou propiciar-lhes deslocamentos, a imaginação cria o território necessário à mobilidade das imagens e ao estabelecimento do imaginário. Ou seja, a mentira ou falsear poético torna-se recurso pragmático para a ficcionalização dos fatos e das coisas do mundo real, e para sua duplicação imagética no contexto metafórico da linguagem.

A fim de trazermos mais alguns comentários sobre a problemática do imaginário e o projeto hermenêutico de Gaston Bachelard, vejamos em seguida uma outra passagem do Romance d'A Pedra do Reino, também escolhida com a intenção de sintetizar as reflexões que desenvolvemos até aqui. Trata-se de uma peripécia narrada por Pedro Quaderna, ocorrida quando ainda estudava no seminário.

Certo dia parara para descansar em uma encruzilhada, ao meio-dia. Tirara uma navalha, e a afiara no couro, tomando nas mãos um espelho que carregava em seu bornal. Percebera que havia arranjado, sem querer, elementos perigosos e evocativos. E quando olhou para o espelho que sustentava à fr ente, vira uma onça atrás de si; mas ao virar-se, não havia nada:

Naquele dia, porém, vi logo que a Onça que eu avistava era uma típica 'visagem de Espelho', parecida com aquela que o Diabo tinha proporcionado ao Estudante de Salamanca nas estradas poeirentas da Castela espanhola! (...) eu via que a Onça era mesmo formada pelas pedras, o mato, as estradas, o Sol, de modo que, refletida no Espelho diabólico, eu estava envolvido por ela, colocado no próprio campo de pêlos de seu dorso. (...) 0 pior, porém, é que não se tratava nem de uma Onça digna, uma Onça Malhada (...). Era uma Onça enorme e mal definida, leprosa, desdentada, sarnenta e escarninha, uma Entidade malfazeja que, ao mesmo tempo que me envolvia e tragava, era tragada, também, aos poucos, por um Buraco perigoso, oco e vazio, cheio de cinza. (Suassuna 2010: Folheto LXXI, 537ss).

A superfície espelhada e a imagem classificada como "visagem de espelho" tornamse presenças evocativas para o que buscamos compreender como imaginário ficcional, e remete-nos aos mesmos mecanismos dos quais se apropriou o cinema, este enquanto 
fenômeno mecânico de duplicação da realidade em um sonho que se sonha de olhos abertos. Recordamos Edgar Morin, para quem o espelho do cinematógrafo pode refletir o mundo: "o cinema dá-nos, não só o reflexo do mundo, mas também o do espírito humano." (Morin 1970: 241), diz Morin. Diferindo-se, estruturalmente, do que encontramos no cinema, a experiência de reflexão com a qual se depara Pedro Quaderna, na passagem supracitada, mesmo originada na superfície refletora de um espelho (uma espécie de auxiliar mágico-diabólico), resulta em uma imagem assombrosa que se encontra totalmente pertencente aos domínios de seu psiquismo imaginante.

Para Bachelard, um imaginário poético, desejante de metáforas e de alteridades, tende a "abandonar tudo o que se vê e o que se diz em favor do que se imagina." (Bachelard 1990: 3). Por mais assombrosa e aterradora que possa ser sua aparição, uma "visagem de espelho" é, para o ser que reflete, antes de tudo uma "miragem que fascina". Capaz de arrebatar o ser imaginante, advindo do imobilismo contemplativo do objeto real, esta miragem espectral traduz-se em sonho e ficção, cujo caráter transcendental tem como ponto de partida a própria imanência do objeto que lhe serve de matéria. Segundo o filósofo francês, a compreensão das figuras no espírito dá-se por sua transfiguração, sendo a palavra a mediação para essa transfiguração na linguagem da ficção: "a palavra é uma profecia" (idem: 6), afirma Bachelard.

Nessa segunda passagem do Romance d'A Pedra do Reino, encontramos um narrador imaginante que, por meio de um procedimento ritualístico e do auxílio de um instrumento "mágico" (uma metáfora para a própria "palavra"), assimila, às suas impressões mais íntimas, imbuídas de memória e de fantasia, um sertão físico de formas dispersas (pedras, mato, estradas, Sol), compondo, deste modo, na deformação que sua imaginação promove na percepção do real, uma totalidade imagética, epopeica e mística, dentro dos domínios de seu próprio imaginário sertanejo, no qual encontra, por fim, sua própria posição de ser no mundo: "eu estava envolvido por ela, colocado no próprio campo de pêlos de seu dorso" (Suassuna 2010: Folheto LXXI, 537). 


\section{Considerações finais}

Pudemos verificar, nessa breve leitura comparada de duas passagens narrativas, como o processo de figuração do espaço sertanejo dá-se de modo cada vez mais elaborado no plano de uma ação imaginante. Da recusa à própria capacidade imaginativa, que se encontrava embevecida por um imaginário pregresso, constituído pela imagística de valorosos poetas e acadêmicos do passado, Pedro Quaderna passa ao exercício do devaneio profundo, quando sua ação imaginante faz ampliar um imaginário sertanejo autêntico, tornando-o autor da própria obra imaginária no espírito. A abertura conferida à imaginação faz com que o personagem comece a agir sobre a realidade do sertão que o circunda e o consome.

Na leitura da primeira sequência, encontramos um Pedro Quaderna confrontado pela fixidez e esterilidade da paisagem sertaneja ordinária, e que se põe em contraste com seu imaginário fabuloso, tornando-o incapaz de perceber na própria realidade exterior as raízes da imagística literária que traz dentro de si. Naquele momento, o herói sertanejo sonha pouco, pois se vale dos sonhos de outrém. Nas palavras de Gaston Bachelard:

Sonha-se antes de contemplar. Antes de ser um espetáculo consciente, toda paisagem é uma experiência onírica. Só olhamos com uma paixão estética as paisagens que vimos antes em sonho. (...) A unidade de uma paisagem se oferece como a realização de um sonho muitas vezes sonhado (...). (Bachelard 1989: 5)

Euclydes Villar, como discorremos antes, apropria-se das formas do real e permitese imaginá-las, transformá-las, a imprimir valor estético à paisagem que contempla, cuja impressão terrível determina a imagem espetacular que tal paisagem assume em seu imaginário. Villar ensina que é preciso falsear a realidade serta neja para alçá-la, a partir de suas formas precárias e imprecisas chegar a imagens belas e absolutas, aptas a entrar no reino do imaginário literário.

Tais ensinamentos tornam-se uma constante na trajetória de Pedro Quaderna e se fazem presentes no episódio da visagem especular, que se encontra descrito na segunda passagem destacada do romance. Essas observações nos permitem ver, a partir do que 
afirma Bachelard, que o espaço geopoético é constructo imaginário imanente ao real, e a ação imaginante do poeta, este "eu" que sonha e verbaliza, compõe, deste modo, a trajetória contínua que o conduz da imanência do real à transcendência do imaginário literário. Logo, a imaginação poética se constitui processo verbal, dinâmico, ambíguo e dialético de interação do poeta com o mundo, encerrando, no objeto estético produzido e em suas infinitas significações, a ambivalência psíquica fundamental entre o imaginário e o real, vindo a ser, portanto, a expressão mais autêntica e amplificada do psiquismo humano ${ }^{5}$.

Para Bachelard, “a imagem literária se apresenta em duas perspectivas: a perspectiva de expansão e a perspectiva de intimidade" (Bachelard 1990: 274). A imagem geopoética de uma Onça-mundo, figurada no romance pelo devaneio de seu narrador, é imagem luminosa e totalizadora, representação das potencialidades de significação que a linguagem literária pode determinar na composição de um imaginário sertanejo profundo e, ao mesmo tempo, expansivo. A figura felina não só assume a perspectiva da intimidade, produto do psiquismo engenhoso de um sertanejo decifrador, como também se expande enquanto figuração de um imaginário sertanejo além de si mesmo:

O pior, porém, é que não se tratava nem de uma Onça digna, uma Onça Malhada (...). Era uma Onça enorme e mal definida, leprosa, desdentada, sarnenta e escarninha, uma Entidade malfazeja que, ao mesmo tempo que me envolvia e tragava, era tragada, também, aos poucos, por um Buraco perigoso, oco e vazio, cheio de cinza. (Suassuna 2010: Folheto LXXI, 538)

“Na terra natal materializamos nossos devaneios", afirma Bachelard (1989: 9). Nesse trecho do romance, deparamo-nos com um sertão metafórico, mítico e profético, cujas formas altamente evocativas redimensionam o sertão real para o espaço irreal da literatura, iluminado pelos efeitos imagéticos, desveladores de sentidos profundos jamais divisados por uma consciência entorpecida, incapaz de sonhar. As impressões imagéticas dessa Onça mundo refletem a superação de uma realidade mesquinha e esquecida, ao mesmo tempo que se afirmam como amplificação de sua miséria e infortúnio (ressaltam-se os adjetivos: mal definida, leprosa, desdentada, sarnenta e escarninha). Imagem diametralmente oposta à beleza idealizada pelo espírito, a Onça Malhada, a Onça-mundo é, todavia, 
verdadeiramente bela enquanto espaço geopoético criado pelo imaginário narrativo, a permitir ao ser humano (re)conhecer o mundo e a si mesmo nesse mundo através da produção de suas imagens.

Constatamos, por fim, na ordenação das impressões sertanejas de Pedro Quaderna, sua asso ciação lúcida e fraterna com um sertão humano e universal, pensado e sonhado em sua imaginação poética. Idealizando uma obra capaz de reunir em si toda uma literatura, Pedro Quaderna, a inventar seu próprio sertão a partir das conchambranças de seu imaginário, transfigura em força e monstruosidade épicas imagens originadas tanto do tempo passado mantido pela memória quanto do espaço presente composto pela narração, a fazer assim do falsear das formas estreitas e imprecisas da geopoética ficcional o fundamento de sua narração transfiguradora.

\section{NOTAS}

10 diálogo entre a psicanálise e os estudos da linguagem estão presentes desde sempre na teoria psicanalítica. Propusemos, nesta passagem, uma tradução semiótica, próxima à perspectiva lacaniana, de alguns conceitos psicanalíticos, verificando que as energias pulsionais investidas sobre as representações imagéticas modificam ou mesmo caracterizam a significação de tais significantes imagéticos. Segundo Nasio, em Freud, o mecanismo de condensação de energia corresponde à figura da metonímia, segundo a qual uma única representação concentra todas as significações; e o mecanismo do deslocamento corresponde à figura da metáfora, na qual as representações se veem atribuir sucessivamente, uma por uma, todas as significações. Observa-se, por outro lado, que essa relação se inverte para Lacan: a condensação é da alçada da metáfora, e o deslocamento, da alçada da metonímia. (Nasio 1995: 19).

N. ${ }^{3} 38-6 / 2018$ | 391-406 - ISSN 2183-2242 | http:/dx.doi.org/10.21747/21832242/litcomp38v5 
2 "Mijo-de-mocó" corresponde a uma expressão sertaneja para "manchas ferrujosas de líquenes secos" (Suassuna 2010: 147). Nota-se que a própria expressão escolhida por Quaderna expressa o caráter desmoralizador que a percepção do real imprimia, para ele, à imagem das pedras do reino.

3 Para compreensão desta passagem, tomamos o verbo "figurar" nas seguintes acepções: "traçar a figura, a imagem não necessariamente fiel de (alguém ou algo); representar; representar alegoricamente; simbolizar, significar." (Dicionário Houaiss da Língua Portuguesa 2001).

40 vigor e a intensidade das imagens que buscamos evidenciar como produto de uma linguagem altamente metafórica leva-nos a considerar, principalmente, os sentidos figurados que os adjetivos conferem à substância que caracterizam. Nesse caso, o adjetivo "férreo" pode derivar os sentidos figurados: "que traz a marca da maldade; cruel, desumano, ferrenho." (Dicionário Houaiss da Língua Portuguesa 2001). Cabe aqui esclarecer, também, que as Pedras do Reino foram, no ano de 1838, palco e altar para o sacrifício de mulheres, crianças e cachorros, realizados por Dom Ferreira Quaderna, o Execrável, que esperava desencantar o castelo de D. Sebastião lavando com sangue inocente suas torres de pedra.

5 “A imagem literária é uma realidade física que tem um relevo especial; mais exatamente, é o relevo psíquico, o psiquismo em vários planos. Ela grava ou eleva. Reencontra uma profundidade ou sugere uma elevação." (Bachelard 1990: 260). 


\section{Bibliografia}

Bachelard, Gaston (1989), A água e os sonhos, trad. Antônio de Pádua Danesi, São Paulo, Martins Fontes.

-- (1990), O ar e os sonhos: ensaio sobre a imaginação do movimento, trad. Antônio de Pádua Danesi, São Paulo, Martins Fontes.

-- (1988), A poética do devaneio, trad. Antônio de Pádua Danesi, São Paulo, Martins Fontes.

Francastel, Pierre (1982), A realidade figurativa: elementos estruturais de sociologia da arte, trad. de Mary Amazonas Leite de Barros, São Paulo, Perspectiva.

Houaiss, Antonio (2001), Dicionário Houaiss da língua portuguesa, Morin, Edgar (1970), O cinema ou o homem imaginário, trad. A.-P. Vasconcelos, Lisboa, Moraes.

Nasio, Juan David (1995), Introdução às obras da psicanálise, trad. V. Ribeiro, Rio de Janeiro, Zahar.

Suassuna, Ariano (2010), Romance d'A Pedra do Reino e o príncipe do sangue do vai-evolta, Rio de Janeiro, José Olympio [1978].

Wunenburger, Jean-Jacques (2000), O Imaginário, trad. M. S. Gonçalves, São Paulo, Edições Loyola. 
Giuliarde de Abreu Narvaes possui licenciatura em Letras pela Universidade Estadual Paulista - Júlio de Mesquita Filho (2011) e mestrado em Letras pela mesma universidade (2014). Tem experiência na área de Letras, com ênfase em literatura comparada, atuando principalmente nos seguintes temas: teorias do imaginário, teoria do romance, crítica psicanalítica, memória e imaginação, teorias comparativas e do cinema e relações homológicas entre literatura, pintura e cinema. 